\title{
Morphological Control of Metal Oxide for Semiconductor-Based Gas Sensor ${ }^{\dagger}$
}

\author{
Takeshi Hashishin ${ }^{1, *}$, Jian Sun ${ }^{2}$, Kazuyoshi Sato ${ }^{3}$ and Hiroshi Kubota ${ }^{2}$ \\ 1 Faculty of Advanced Science and Technology, Kumamoto University, 2-39-1 Kurokami, Chuo-ku, \\ Kumamoto 860-8555, Japan \\ 2 Graduate School of Science and Technology, Kumamoto University, 2-39-1, Kurokami Chuo-ku, \\ Kumamoto 860-8555, Japan; 186d8884@st.kumamoto-u.ac.jp (J.S.); kubota@cs.kumamoto-u.ac.jp (H.K.) \\ 3 Graduate School of Science and Technology, Gunma University, 1-5-1 Tenjin-cho, Kiryu, \\ Gunma 376-8515, Japan; kazuyoshi-sato@gunma-u.ac.jp \\ * Correspondence: hashishin@msre.kumamoto-u.ac.jp \\ + Presented at the 8th GOSPEL Workshop. Gas Sensors Based on Semiconducting Metal Oxides: Basic \\ Understanding \& Application Fields, Ferrara, Italy, 20-21 June 2019.
}

Published: 19 June 2019

Morphological control of metal oxide (MO) is important for enhancement of sensing properties such as sensor response and response-recovery characteristics. Our research group has been developed $\mathrm{MO}$ based gas sensors fabricated by $\mathrm{WO}_{3}$ and $\mathrm{SnO}_{2}$ nanocrystals synthesized by hydrothermal method for high sensor response to $\mathrm{NO}_{2}$ or $\mathrm{H}_{2}[1,2]$. On the other hand, shuttle-shape $\mathrm{SnO}_{2}$ showed the sensor response to $\mathrm{NO}_{2}$ and $\mathrm{H}_{2} \mathrm{~S}$ at room temperature.

The film sensor with cuboid-shape monoclinic $\mathrm{WO}_{3}$ nanocrystal (Figure 1a) showed sensor response ( $\mathrm{Rg} / \mathrm{Ra}$ ) of $10^{2}-10^{4}$ to $0.05-1 \mathrm{ppm} \mathrm{NO}$ at $200{ }^{\circ} \mathrm{C}$ (Figure 1c). In contrast, the sensor with hexagonal-shape hexagonal $\mathrm{WO}_{3}$ nanocrystal (Figure $1 \mathrm{~b}$ ) showed sensor response lower one order of magnitude than that with cuboid-shape monoclinic $\mathrm{WO}_{3}$ in above same detection condition (Figure 1d). This difference was related to surface states. XPS spectra of O1s showed that the content of $\mathrm{OH}^{-}$ was larger for hexagonal-shape hexagonal $\mathrm{WO}_{3}\left(\mathrm{O}^{2-} / \mathrm{OH}^{-} / \mathrm{H}_{2} \mathrm{O}\right.$ (in \%) $=60.0 / 38.1 / 1.9$, in Figure 1e) than for cuboid-shape monoclinic $\mathrm{WO}_{3}$ (80.4/4.9/14.7, in Figure 1f). The results suggested that the high content of oxygen adsorbate $\left(\mathrm{O}^{2-}\right)$ on the surface of $\mathrm{WO}_{3}$ could be contributed to higher sensor response.
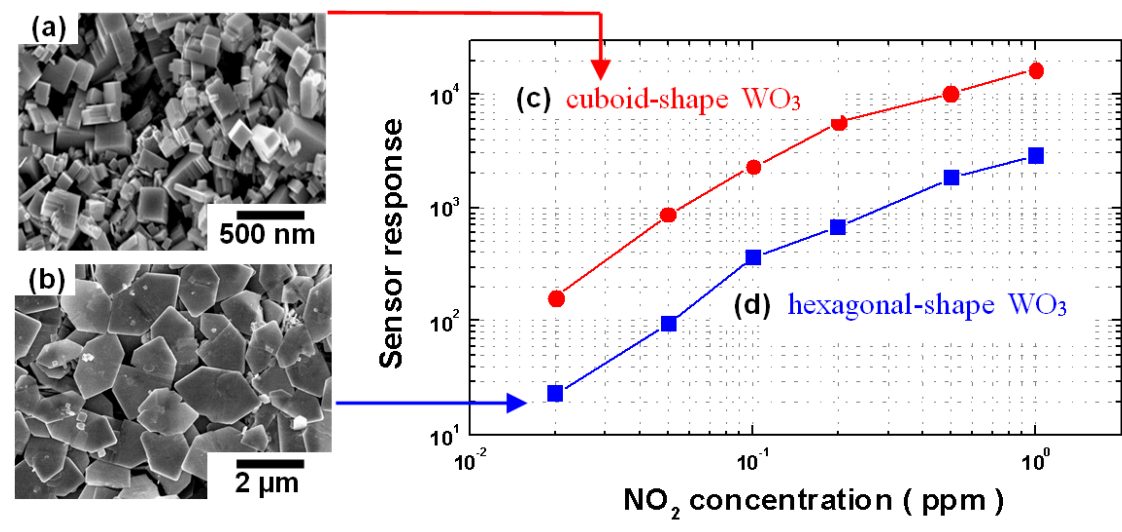

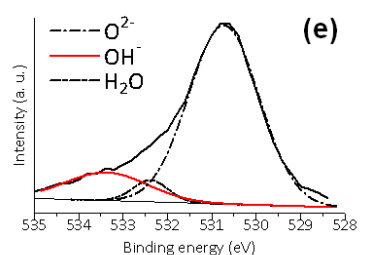

Binding energy (eV)

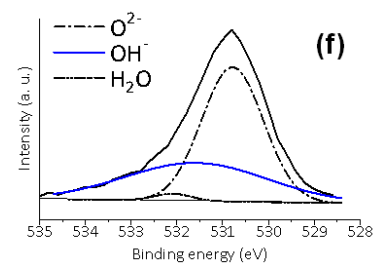

Figure 1. FE-SEM images of (a) cuboid-shape monoclinic $\mathrm{WO}_{3}$ nanocrystal and (b) hexagonal-shape hexagonal $\mathrm{WO}_{3}$ nanocrystal. Sensor response as a function of $\mathrm{NO}_{2}$ concentration for (c) cuboid-shape $\mathrm{WO}_{3}$ and (d) hexagonal-shape $\mathrm{WO}_{3}$. XPS spectra of $\mathrm{O} 1 \mathrm{~s}$ on the surface of (e) as-prepared cuboid-shape $\mathrm{WO}_{3}$ and (f) hexagonal-shape $\mathrm{WO}_{3}$. 

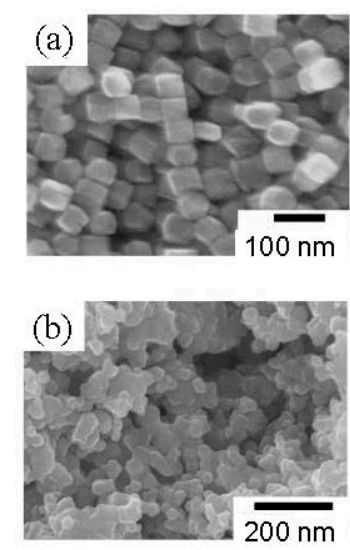

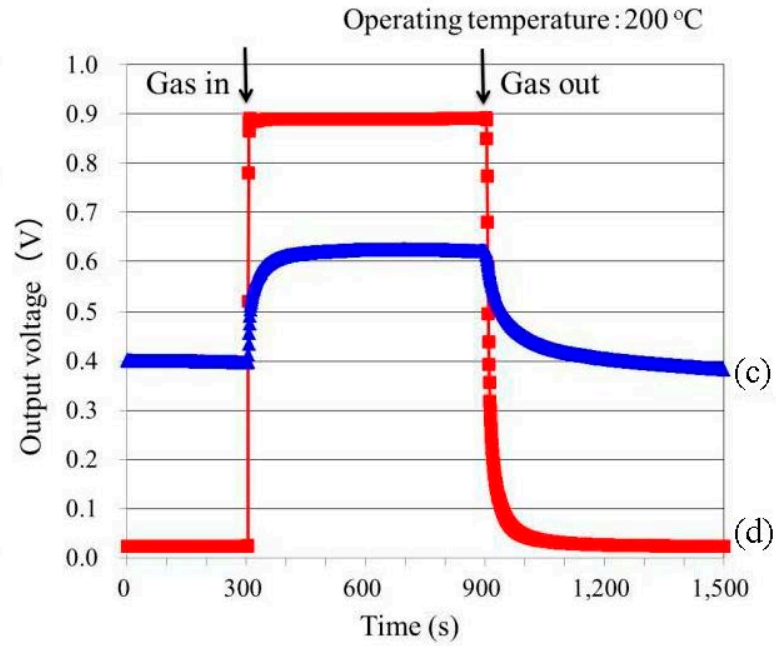

Figure 2. FE-SEM images of (a) $\mathrm{SnO}_{2}$ nanocubes annealed at $250{ }^{\circ} \mathrm{C}$ for $3 \mathrm{~h}$ and (b) commercial $\mathrm{SnO}_{2}$ nanoparticles calcined at $1100{ }^{\circ} \mathrm{C}$. Response- recovery transients of (c) and (d) to respective gas mixture of $1000 \mathrm{ppm}_{2}$ and air.

\section{References}

1. Meng, Z.; Fujii, A.; Hashishin, T.; Wada, N.; Sanada, T.; Tamaki, J.; Kojima, K.; Haneoka, H.; Suzuki, T. Morphological and crystal structural control of tungsten trioxide for highly sensitive $\mathrm{NO}_{2}$ gas sensors. J. Mater. Chem. C 2015, 3, 1134-1141.

2. Sato, K.; Yokoyama, Y.; Valmalette, J.C.; Kuruma, K.; Abe, H.; Takarada, T. Hydrothermal Growth of Tailored $\mathrm{SnO}_{2}$ Nanocrystals. Cryst. Growth. Des. 2013, 13, 1685-1693.

(c) 2019 by the authors. Licensee MDPI, Basel, Switzerland. This article is an open access article distributed under the terms and conditions of the Creative Commons Attribution (CC BY) license (http://creativecommons.org/licenses/by/4.0/). 